\title{
Ruptured cornual ectopic pregnancy at 8 weeks gestation- successful conservative approach: a case report
}

\author{
Shobha S. Shiragur*, Vijayalaxmi Gobbur R, Manpreetkaur Tehalia J, \\ Rathi Doshi, Sreedevi Kori
}

\begin{abstract}
Department of Obstetrics \& Gynaecology, Bijapur Liberal District Educational University's Shri B.M. Patil Medical College Hospital and Research Centre Bijapur-586103, Karnataka, India
\end{abstract}

Received: 16 August 2013

Accepted: 5 September 2013

*Correspondence:

Dr. Shobha S. Shiragur,

E-mail: shiragur1208@gmail.com

(C) 2013 Shiragur SS et al. This is an open-access article distributed under the terms of the Creative Commons Attribution Non-Commercial License, which permits unrestricted non-commercial use, distribution, and reproduction in any medium, provided the original work is properly cited.

\begin{abstract}
Cornual pregnancy is a rare form of ectopic pregnancy that usually leads to uterine rupture with resultant life threatening hemorrhage. The mortality of interstitial pregnancies is more than twice that of other tubal pregnancies. Cornual pregnancies often rupture later than other tubal pregnancies because the myometrium is more distensible than the fallopian tube. We report a case where a patient presented at 8 weeks of gestational age with ruptured cornual ectopic pregnancy and hemoperitoneum. Emergency Laparotomy was done and cornual rupture was sutured successfully. Close monitoring of pregnancies in these patients is important to prevent a deleterious delay in treatment of a cornual pregnancy
\end{abstract}

Keywords: Cornual, Ectopic, Pregnancy, Laparotomy

\section{INTRODUCTION}

The interstitial part of the fallopian tube is the proximal portion that lies within the muscular wall of the uterus. It is $0.7 \mathrm{~mm}$ wide and approximately $1-2 \mathrm{~cm}$ long, with a slightly tortuous course extending obliquely upwards and outwards from the uterine cavity. Pregnancies implanted in this site are called as interstitial or cornual pregnancies. Cornual gestation is one of the most hazardous types of ectopic gestation which may often require hysterectomy. Cornual pregnancies account for $2-4 \%$ of ectopic pregnancies and is said to have a mortality rate in the range of 2.0-2.5\%. Risk factors are as for other types of ectopic pregnancies such as contralateral salpingectomy, previous ectopic pregnancy, pelvic inflammatory disease, smoking, IUCD and progesterone only pills, in utero DES exposure, increasing age. Until recently cornual ectopic or interstitial pregnancies have been treated by Laparotomy with cornual excision or Hysterectomy. However, recently increasingly there have been attempts to add Laparoscopic conservative management as a treatment option. Here we present a case where conservative cornual repair was done.

\section{CASE REPORT}

A 20 year old, G2P1L1 presented to labour room with the complaint of acute abdominal pain at 8 weeks gestational age. She had severe abdominal pain 2 hours before admission associated with vomiting. She was afebrile with severe pallor and pulse rate being 110/min and BP 100/60 mm of $\mathrm{Hg}$. Per abdominal examination revealed severe tenderness in the left lower quadrant with positive shifting dullness; Pelvic examination revealed uterus retroverted with bilateral fornicial tenderness and cervical motion tenderness. Emergency USG done showed $67 * 70 \mathrm{~mm}$ sized mixed echogenic area seen in pelvis surrounding the uterus with evidence of 'ring of fire sign' in right adnexa in the cornual region with moderate free fluid and internal echoes suggesting hemoperitoneum. 
Findings were suggestive of Ruptured cornual ectopic pregnancy. Her immediate laboratory tests included $\mathrm{Hb}$ $4.4 \%, \mathrm{BT} / \mathrm{CT}$ within normal limits, blood group was AB positive and HIV and HBsAg being negative. Past obstetric history she had a full term Emergency LSCS done $1 \frac{1}{2}$ years back for fetal distress, delivered female baby alive and healthy. Consent was taken for Emergency Laparotomy and the patient was asked to arrange for 4 units of blood. Emergency Laparotomy was done under General Anaesthesia. There was about $2000 \mathrm{ml}$ of blood in the abdominal cavity with $250 \mathrm{gms}$ of clots. Ruptured right corneal ectopic seen with bilateral tubes and ovaries being normal (Figure 1). Cornual repair was done with Vicryl no1 (Figure 2). Hemostasis obtained and after ensuring instrument and mop count abdominal wall was closed in layers. Post operatively, she was transfused with 4 units of whole blood. The post operative course was uneventful and she was discharged on day 7 in good condition.

\section{DISCUSSION}

Cornual pregnancy is diagnosed with ultrasonographical criteria in presence of positive hCG indicating pregnancy. These criteria include: 1) An empty uterus 2) A gestational sac seen separately and more than $1 \mathrm{~cm}$ from the most lateral edge of the uterine cavity 3) A thin myometrial layer surrounding the sac.

A thin echogenic line extends into the cornual region abuting the gestational sac and this is called 'The interstitial line sign'. This interstitial line can be either the endometrial cavity or the interstitial portion of the fallopian tube. USG in our case showed a $67 \times 70 \mathrm{~mm}$ sized mixed echogenic area in right cornual region. Early diagnosis of cornual pregnancy with TVS allows for first trimester conservative management with Methotrexate.

Tulandi et al, reviewed the management of 32 reported cases of cornual pregnancy. Ultrasound revealed an ectopic cornual gestational sac in $40.6 \%$ of women and a hyperechoic mass in the cornual region in another $25 \%$. The diagnosis was established in $71.4 \%$ of 32 women with sensitivity of $80 \%$ and specificity of $99 \%$. 4D volume contrast imaging can differentiate between angular and cornual pregnancy. In angular pregnancy embryo is implanted medial to the utero tubal junction and round ligament while in cornual pregnancy embryo is implanted lateral to the round ligament.

Peterson et al reported a case of uterine cornual rupture following attempted mid trimester induced abortion for presumed intrauterine pregnancy. They stated that physicians should consider ectopic pregnancy when attempts at induced abortion do not succeed.

Traditionally, the treatment of cornual pregnancy has been Hysterectomy or cornual resection at Laparotomy. As all surgical management has been associated with morbidity and unfavourable effects on fertility, more conservative approaches have been introduced into clinical practice. Conservative techniques such as Laparoscopic cornual resection, Laparoscopic cornuostomy or hysteroscopic removal of interstitial ectopic tissue, unilateral uterine artery ligation have been tried. Medical methods such as systemic Methotrexate is safe and highly effective treatment for cornual pregnancy, so that surgery can be avoided.

Outpatient presented relatively in an early gestation with cornual rupture we could achieve hemostasis just by repairing the ruptured area. Cornual pregnancy can cause significant maternal mortality and morbidity. Early diagnosis aided by USG or Laparoscopy may help to contribute towards effective conservative management.

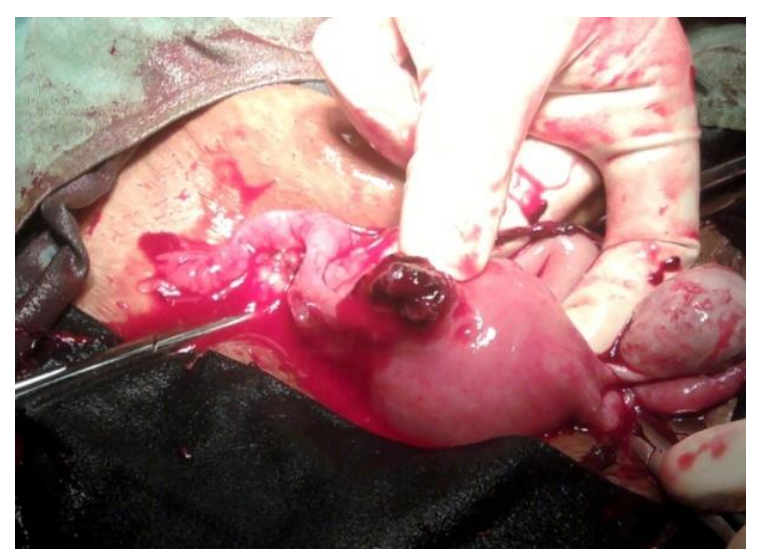

Figure 1

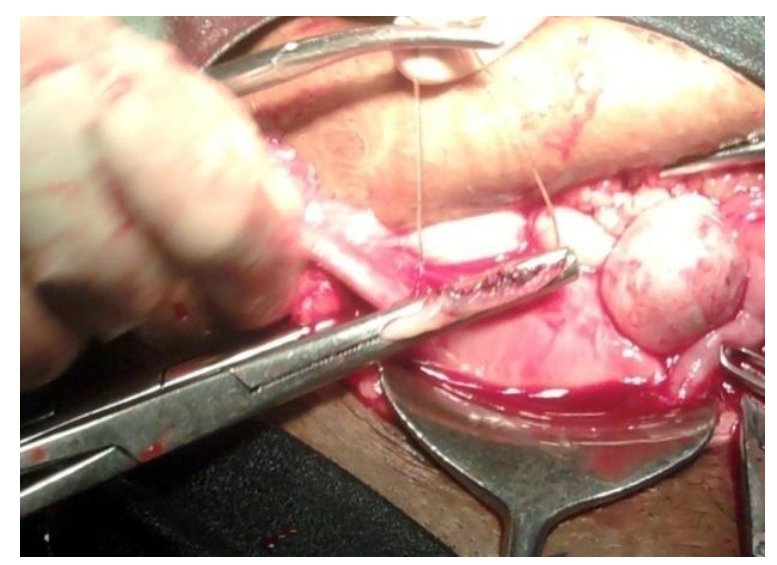

Figure 2

\section{REFERENCES}

1. Confidential Enquiry into Maternal and Child Health. Why Mothers Die 2000-2002. The Sixth Report of the Confidential Enquiries into Maternal Deaths in the United Kingdom. London: RCOG Press; 2004.

2. Tulandi T, Al-Jaroundi D. Interstitial pregnancy: results generated from the Society of Reproductive Surgeons Registry. Obstet Gynaecol. 2004;103:4750 . 
3. Jean B, Joel C, Taraneh S, Jean-Luc P, Herve F, Laurent $G$ and Nadine JS. Risk factore for ectopic pregnancy: a comprehensive analysis based on large case-control population-based study in France. Am J Epidemiol, 2002;157(3): 185-194.

4. JJ Beltman and CJM Groot. Cornual pregnancy as a complication of the use of a levonorgestrel intrauterine device: a case report. Journal of medical case reports.2009; 3:8387.
5. Ankum WM, Mol BW, Vanderveen F, Bossuyt PM. Risk factors for ectopic pregnancy: a meta-analysis. Fertilsteril, 1997;67(4): 791-792.

6. Timor-Tritsch IE, Monteagudo A, Matera C, Veit CR. Sonographic evolution of cornual pregnancies treated without surgery. Obstet Gynaecol 1992;79: 1044-9.

DOI: $10.5455 / 2320-1770 . i j r \operatorname{cog} 20131235$

Cite this article as: Shiragur SS, Gobbur RV, Tehalia JM, Doshi R, Kori S. Ruptured cornual ectopic pregnancy at 8 weeks gestation- successful conservative approach: a case report. Int J Reprod Contracept Obstet Gynecol 2013;2:671-3. 